\title{
Celebrar a los indígenas, defender al indigenismo: el "Día del Indio" y el Instituto Indigenista Interamericano*
}

\author{
Homenagear os índios, defender o indigenismo: \\ o "Dia do Índio" e o Instituto Indigenista Interamericano \\ Celebrating the Indian, defending the indigenismo: \\ the "Indian Day" and the Inter-American Indian Institute
}

\section{Laura Giraudo**}

\begin{abstract}
Resúmen: En 1940, el Primer Congreso Indigenista Interamericano de Pátzcuaro (México) estableció el 19 de abril de cada año como "Día del Indio", para recordar la fecha en que los delegados indígenas se sumaron al Congreso. El artículo analiza la creación de esta nueva celebración por parte de los indigenistas que estaban, al mismo tiempo, fundando el Instituto Indigenista Interamericano (III), con el objetivo de definir y desarrollar una política común acerca de la "cuestión indígena". En primer lugar, nos ocuparemos de la adopción oficial del Día del Indio durante el apogeo del indigenismo (1940-1970), discutiendo si se trasformó en la celebración indigenista continental que esperaban sus promotores. En segundo lugar, "el análisis de los discursos oficiales pronunciados por los directores" y los representantes del III con la ocasión de la celebración, sugiere que el Día del Indio ofrecía un escenario útil para un relato sobre el pasado y el presente de los indígenas y de los países americanos, mientras asignaba al indigenismo un papel crucial. De hecho, el Día del Indio, tanto en el ámbito interamericano como en los diferentes ámbitos nacionales, funcionó más como práctica identificadora de los defensores del indigenismo y de las políticas indigenistas que como homenaje a los indígenas.
\end{abstract}

Palabras clave: indigenismo; indigenas; celebraciones; Día del Indio; Instituto Indigenista Interamericano.

Resumo: Em 1940, o Primeiro Congresso Indigenista Interamericano de Pátzcuaro (México) estabeleceu o 19 de abril de cada ano como "Dia do Índio", para relembrar a data em que os delegados indígenas somaram-se ao Congresso. O artigo analisa a criação desta nova comemoração pelos indigenistas que, ao mesmo tempo, estavam a fundar o Instituto Indigenista Interamericano (III) com o objetivo de definir e desenvolver uma política comum a respeito da "questão indígena". Abordaremos em primeiro lugar a adoção oficial do Dia do Índio durante o apogeu do indigenismo (1940-1970) discutindo se ele se transformou na comemoração indigenista que os seus criadores esperavam. Em segundo lugar, a análise dos discursos oficiais pronunciados pelos diretores e representantes do III com ocasião da comemoração sugere que o Dia do Índio oferecia um palco útil a um relato sobre o passado e o presente dos indígenas e dos países americanos, no qual reservava um papel crucial ao indigenismo. De fato, o Dia do Índio, tanto no âmbito interamericano quanto nos diferentes espaços nacionais, agiu mais como uma pratica identificadora dos defensores do indigenismo e das políticas indigenistas que como uma homenagem aos indígenas.

Palavras-chave: indigenismo; indígenas; celebrações; Dia do Índio; Instituto Indigenista Interamericano.

\footnotetext{
* Este trabajo es resultado del Proyecto de Investigación RE-INTERINDI "Los reversos del indigenismo: socio-historia de las categorías étnico-raciales y sus usos en las sociedades latinoamericanas" (Secretaría de Estado de Investigación, Desarrollo e Innovación, Ministerio de Economía y Competitividad, España, HAR2013-41596-P). Agradezco a los evaluadores, además de sus comentarios acerca de este artículo, sus reflexiones y sugerencias sobre otros aspectos de este tema que aquí no fue posible abordar, pero que espero desarrollar en el futuro.

** Investigadora de la Escuela de Estudios Hispano-Americanos del Superior de Investigaciones Científicas (EEHA-CSIC), en Sevilla, España. dados biográficos_biographic data
} 


\begin{abstract}
The First Inter-American Indian Conference, held in Pátzcuaro (Mexico) in 1940, resolved to set aside April 19 of each year as "Indian Day" throughout the Americas to commemorate the date on which the Indian delegates joined the Conference. This article examines the creation of this new holiday by indigenistas who were at the same time founding the Inter-American Indian Institute (III) for the purpose of defining and developing a common policy about the "Indian problem". I will first focus on the official adoption of Indian Day during the heyday of indigenismo (1940-1970), and discuss whether (or not) it became the hemispheric indigenista holiday envisioned by its creators. Secondly, the analysis of official speeches that the director and representatives of the III gave on occasion of the holiday will suggest that the Indian Day offered a useful scenario for an historical and present-day narrative about Indian People and Latin American countries, while assigning a crucial role to indigenismo. Actually, I will argue, the significance of the Indian Day, beyond its explicit tribute to the Indian, was rather related to the defense of indigenismo and the indigenista policies, at both the inter-American and the national level.
\end{abstract}

Keywords: indigenismo; celebrations; Indigenous people; Indian Day; Inter-American Indian Institute.

\section{¿Desde Alaska hasta Patagonia? La supuesta "americanidad" de una celebración}

En 1961, el director del Instituto Indigenista Interamericano, Miguel León-Portilla, afirmaba que "el 19 de abril ha sido adoptado por la gran mayoría de las naciones americanas para recordar el pasado grandioso y el presente abundante en problemas de 30 millones de indígenas"1. Esta festividad, el "Día del Indio", había sido introducida en 1940 por el Primer Congreso Indigenista Interamericano, reunido en Pátzcuaro, México, pronto convertido en momento y lugar simbólicos del indigenismo continental, tanto para sus defensores como para sus críticos. Entre las 72 resoluciones adoptadas en Pátzcuaro, la más dirigida a perpetuar lo simbólico del momento y a celebrar la que en varias ocasiones se definiría como una "raza olvidada" era precisamente la que se refería al "Día del Indio" (INSTITUTO INDIGENISTA INTERAMERICANO, 1940).

Según el relato oficial de la propia resolución, la recomendación provino de los delegados indígenas de Panamá, Chile, Estados Unidos y México y fue presentada por el representante panameño, Rubén Pérez Kantule". Se consideraba "que es bueno que los grupos indígenas de América tengan ocasión de encontrar el espíritu de su raza en una misma fecha cada año" y que, a pesar de que en varios países existen "fechas diversas dedicadas a enaltecer al indio", es

1 "Editorial. Conmemoración del Día del Indio", BI, v. 21, n. 2, p. 82, jun. 1961.

2 Solo tres países contaban, oficialmente, con "delegados indígenas": Estados Unidos (14), México (32) y Panamá (1). La resolución hace probablemente referencia a César Colima y Venancio Coñuepan, dirigentes de la Corporación Araucana, que participaron en la delegación gubernamental de Chile (VERGARA, GUNDERMANN, 2016). digno de conmemorarse la reunión de representantes indígenas ocurrida "por primera vez" en Pátzcuaro. A tal fin se hacían dos recomendaciones:

Primero. Que los Gobiernos de los países Americanos establezcan el "Día del Indio" dedicado a estudiar en todas las Escuelas y Universidades, con criterio realista, el problema del indio actual. Segundo. Que los países de América adopten el día 19 de abril, como Día Americano del Indio para conmemorar la fecha en que por primera vez se reunieron los Delegados Indígenas al Primer Congreso Indigenista Interamericano en la Posada de Don Vasco de Quiroga en Pátzcuaro, Michoacán, República Mexicana (INSTITUTO INDIGENISTA INTERAMERICANO, 1940, p. 32).

Se trata de una conmemoración que está dedicada "al indio" (como sujeto atemporal), pero que se refiere a los destinatarios del ambicioso programa de política indigenista continental que se quería poner en marcha (el "indio actual") y, al mismo tiempo, se presenta como homenaje directo a un momento especial en el Congreso de Pátzcuaro, en el que adquieren visibilidad los "indios indigenistas" (los delegados y los demás participantes indígenas). Además, la resolución posibilita dos celebraciones, incluso con denominaciones distintas, teniendo en cuenta la existencia previa de "días del indio" en algunos países: un "Día del Indio" en cada país con una orientación pedagógica (en fechas diferentes según los casos) y un "Día Americano del Indio", con una orientación conmemorativa, establecido en la fecha del 19 de abril.

Veinte años después de su introducción, según afirmaba León-Portilla en 1961, la celebración habría alcanzado una difusión continental, como recoge el órgano de información del III, el Boletín Indigenista, 
que representa una muestra significativa de la trayectoria de esta "nueva" conmemoración, que el propio Instituto quería difundir y considerar un éxito ${ }^{3}$. Según la información publicada en el Boletín, 16 países americanos (además de un país europeo) celebraron el Día del Indio durante ese periodo, pero no todos, como veremos, lo hicieron en la fecha establecida en 1940 o según los criterios fijados por el Congreso de Pátzcuaro. La mayor parte de los países establecieron la festividad a inicio de la década de 1940, pero algunos ya contaban con un día dedicado al "indio" y lo mantuvieron, y Guatemala la estableció solo en $1959^{4}$.

El mayor número de noticias en el periodo 19411961 se refiere a festejos realizados en México, Brasil y Argentina.

México representa un caso especial. En 1940 acogió el Primer Congreso Indigenista Interamericano -oficiando como anfitrión y gran protagonista- $y$ desde entonces mantuvo la sede "provisional", que nunca se cambió, del III, organismo intergubernamental especializado que aspiraba a convertirse en el defensor y hacedor de la política indigenista en todo el continente americano (GIRAUDO 2011 y 2012). Su director provisional fue, por breve periodo, el propio organizador del congreso, el mexicano Moisés Sáenz y, desde marzo de 1942, Manuel Gamio, quien lo dirigirá hasta 1960, todo el periodo en que se publicó el Boletín. Es importante recordar que de todos los directores del III, la mayoría (seis de diez) fueran mexicanos ${ }^{5}$. Por todo lo anterior, no sorprende que el mayor número de noticias se refiera a este país, donde el propio III organizaba la celebración oficial "interamericana", si bien es difícil distinguir ésta de la celebración "mexicana", organizadas conjuntamente entre el Instituto y ese gobierno nacional. Así, el caso mexicano no puede considerarse propiamente "nacional", de la misma manera en que las actividades del III cada 19 de abril no pueden separarse de las celebraciones

\footnotetext{
3 En 1945, en el propio Boletín Indigenista se hace un llamamiento a los lectores para que informen sobre los actos de celebración del Día del Indio. $B I$, v. 5, n. 1, p. 2, mar. 1945.

4 "Guatemala. Informe del Instituto Indigenista Nacional: 1959", $B I$, v. 20, n. 2, p. 130, jun. 1960. A pesar de su introducción tardía, el "Día del aborigen", como se le llamó en Guatemala, tuvo bastante continuidad en la época posterior, cfr. INSTITUTO INDIGENISTA NACIONAL, 1970.

5 Moisés Sáenz, mexicano (1940-1941), Carlos Girón Cerna, guatemalteco (interino, 1941), Manuel Gamio, mexicano (19421960), Miguel León Portilla, mexicano (1961-1966), Gonzalo Aguirre Beltrán, mexicano (1967-1971), Gonzalo Rubio Orbe, ecuatoriano (1971-1977), Oscar Arze Quintanilla, boliviano (19771989), José Matos Mar, peruano (1989-1995), José del Val Blanco, mexicano (1995-2001), Guillermo Espinosa Velasco, mexicano (honorario, 2002-2009).
}

mexicanas. En un primer periodo, el III celebró el Día del Indio con la Secretaría de Educación Pública (SEP) y el Departamento de Asuntos Indígenas (DAI) mexicanos, hasta que apareció el Instituto Nacional Indigenista (INI), fundado en 1948 y dirigido hasta 1970 por Alfonso Caso, quien se convirtió en uno de los actores protagonistas del evento, si bien la SEP siguió participando a través de la Dirección General de Asuntos Indígenas (DGAI) ${ }^{6}$. Esta celebración conjunta consistía fundamentalmente en un programa radiofónico en el que, además de los discursos del director y del representante del comité directivo del III por un lado, y del secretario del DAI, de la DGAI o del director del INI por el otro, había piezas musicales "indígenas".

Brasil, por su parte, introdujo la celebración en 1943, en cumplimiento directo de lo acordado en Pátzcuaro, y desde entonces entró en su calendario festivo y se realizó con regularidad. No es casual esta mayor presencia: Brasil representa, junto a México, el país con mayor continuidad en las políticas indigenistas y el primero en fundar, en 1910, un organismo indigenista nacional, el Serviço de Proteção ao Índios (SPI), sustituido en 1967 por la Fundação Nacional do Índio (FUNAI) (RIBEIRO, 1962; FREIRE, 1990; SOUZA LIMA, 2002 y 2006). En 1951, el secretario del Conselho Nacional de Proteção ao Índios (CNPI) ${ }^{7}$ consideraba tradicional esta festividad que, desde su primera celebración, en 1944, se había ampliado a la "Semana del Indio". En su inicio, el CNPI, el Museo Nacional y el SPI protagonizan la celebración. Con la inauguración del Museu do Indio, el 19 de abril de 1953 en conmemoración del Día del Indio, esta institución toma el relevo hasta el día de hoy, como parte de su misión de producir conocimiento, preservar el patrimonio cultural indígena y difundir una imagen correcta del indio.

A pesar de que no fue hasta 1954 que Brasil se adhirió al III, ratificando la Convención Internacional de 1940, y que nunca se transformó el CNPI en un instituto indigenista nacional como la misma convención preveía, con el Día del Indio se reivindicaba el enfoque continental, el destacado papel de Brasil (y de sus indigenistas, sobre todo Rondón) y su cercanía

\footnotetext{
${ }^{6}$ En México, la SEP fue la principal institución indigenista hasta que se fundó el INI e incluso después siguió manteniendo un papel destacado (DAWSON, 2004; LEWIS, 2011).

7 El CNPI, creado en 1939, era el órgano con competencia en la definición de la política indigenista, mientras al SPI correspondía la ejecución y responsabilidad del servicio.

8 A. dos Santos Oliveira Jr., "Brasil. La tradición celebración de la Semana del Indio", BI, v. 11, n. 3, p. 206-215, sept. 1951.
} 
a México. La versión brasileña del Día del Indio, en la que hay que enfatizar su oficialidad y fuerte presencia de los órganos indigenistas, cumplía sobradamente con las dos vertientes de la resolución de Pátzcuaro, la orientación pedagógica (mediante actividades de difusión y divulgación) y la orientación conmemorativa (de la fecha en sí y de "los indios", pero también en el sentido de auto-celebración indigenista), uniendo en una sola las dos celebraciones, nacional y continental, que la propia resolución hacía posibles.

El tercer país en número de noticias, Argentina, aparece en 1941, antes que el propio III, que sólo lo hará desde 1942. El único otro país presente en 1941 es Panamá, algo bastante comprensible, ya que fue precisamente el delegado indígena panameño quien propuso la resolución que introducía el Día del Indio ${ }^{9}$. A diferencia del Brasil, en Argentina, la celebración nace desde la iniciativa privada, organizada por la Alianza Indo-Americana, en un entorno cultural y artístico en el que el indigenismo es en buena medida nativismo. Esta asociación, activa desde 1939, reivindicaba la celebración en un país que, según declaraban, es el "que padece más las consecuencias de un exagerado extranjerismo y de la negación y postergación de sus elementos nativos - criollos e indios" ${ }^{10}$. El protagonismo de la Alianza Indo-Americana se mantendrá incluso después de que, en cumplimiento de la resolución de Pátzcuaro, se aprobara oficialmente la festividad en $1945^{11}$.

El ámbito privado es relevante también en otros países. Paraguay, a pesar de su pronta adhesión al III (en 1942), no contaba con un instituto indigenista nacional, aunque sí se fundó una asociación indigenista en $1953^{12}$. Y Chile, que creó en 1949 un instituto indigenista, entidad de carácter privado pero con aspiración de afiliarse al III, que colaboró en la organización del Día del Indio, por lo menos en 1952 y 1956, cuando el Día se extendió a la "Semana del

\footnotetext{
9 Es el propio Rubén Pérez Kantule quien remite las noticias: R. Pérez Kantule, "Panamá. Celebración del Día del Indio", BI, v. 1, n. 1, p. 12, agosto 1941; "Panamá. Día del Indio", $B I$, v. 7, n. 3, p. 260, sept. 1947. Son las únicas noticias referentes a Panamá, por lo que la difusión de la celebración en el país de su promotor no parece haber sido muy extendida y, de todas formas, estrechamente relacionada con el proceso político de autonomía de la Comarca de San Blas (denominada actualmente Kuna Yala).

10 "Argentina. Celebración del Día del Indio", BI, v. 1, n. 1, 1941, p. 5, agosto 1941. "Argentina. Carta de la Alianza Indo-americana", $B I$, v. 1, n. 2, p. 19-20, nov. 1941.

11 "Argentina. Declaración oficial del Día del Indio", BI, v. 7, n. 2, p. 118 , jun. 1947.

12 "Paraguay. Día del Indio", BI, v. 3, n. 2, p. 112-116, jun. 1943;

"Paraguay. Con motivo de [sic] Día del Indio", BI, v. 13, n. 3, p. 268-275, sept. 1953 .
}

Indio"13. Sin embargo, las celebraciones del Día del Indio en Chile dejan entrever el muy significativo papel de la Corporación Araucana, y de otras organizaciones indígenas mapuches, en el indigenismo chileno e interamericano, algo que simbólicamente quedó plasmado en el nombre adoptado desde por lo menos 1945: "Corporación Araucana. Movimiento Indigenista de Chile", y el papel ejercido por Venancio Coñuepán, que tras participar en Pátzcuaro fue nombrado ministro de Tierras y Colonización y más tarde director de Asuntos Indígenas (VERGARA, GUNDERMANN, 2016).

Finalmente, sobre Colombia y Ecuador, países donde los institutos indigenistas se fundaron como entidades privadas, contamos con escasas noticias sobre las celebraciones aunque sí son significativas. En 1942, el Instituto Etnológico Nacional de Colombia informaba sobre la alocución radiofónica de Gregorio Hernández de Alba, futuro director del Instituto Indigenista de ese país (fundado en 1943), reclamando más poder y más medios para que los etnólogos colombianos "puedan llegar al indio, a los 105,807 nativos para estudiarlos, mejorarlos y acercarlos a lo que de verdaderamente bueno tenga el país" y "pagar" de esta manera "lo que debemos a los hijos de América" "14. También sabemos que el Día del Indio se celebró al año siguiente y que el recién fundado Instituto Indigenista de Colombia, que todavía no tenía apoyo oficial y funcionaba como entidad privada, envió sobre ello un recordatorio a los distintos grupos indigenas e involucró en el acto de la capital "algunos indigenas paeces de la región de Tierradentro"15. El Instituto Indigenista del Ecuador (IIE) organizó, por su parte, en 1944, dos tipos distintos de actos: el primero en Nayon, cerca de Quito, con "un contenido de servicio, de realización beneficiosa" y de "carácter absolutamente indígena", el segundo

\footnotetext{
13 “Chile. Día del Indio", BI, v. 12, n. 3, p. 230-239, sept. 1952. "Chile. Celebración del Día del Indio", por Álvaro Jara, $B I$, v. 16, n. 2/3, p. 142-145, agosto 1956. El historiador Álvaro Jara había sido el presidente de la delegación chilena al congreso indigenista de $\mathrm{La} \mathrm{Paz} \mathrm{(1954)} \mathrm{y} \mathrm{era} \mathrm{colaborador} \mathrm{del} \mathrm{Instituto} \mathrm{Indigenista}$ Chileno.

14 “Colombia. Día del Indio", BI, v. 2, n. 3, p. 11-12, sept. 1942. ${ }^{15}$ Blanca Ochoa Sierra al director del III el 6/5/1943, AHIII, Colombia, Carpeta "Hernández de Alba, Gregorio". El Instituto contaba con una segundo director, el socialista Antonio García Nossa, organizador de ligas indigenas en el Cauca e invitado especial en el Congreso de Pátzcuaro (TROYAN, 2008). En 1944, se informaba al III sobre la promulgación el 19 de abril del Decreto 918 que disolvía los resguardos indígenas en la región de Tierradentro, añadiendo irónicamente que así se había celebrado "la fiesta del indio". A. Garcia, G. Hernández de Alba y B. Ochoa Sierra a Manuel Gamio el 14/4/1944 (sic), AHIII, Colombia, Carpeta "García, Antonio".
} 
en la Universidad Central, con una sesión solemne de homenaje del IIE, en que se exaltó la figura de la mujer india ecuatoriana. En el primer caso, se inauguraron un puesto de higiene rural, una biblioteca anexa a la escuela y un centro juvenil. En ese acto participó el "profesor indio" Elías Siñalín Chancay, quien afirmó que "él y sus compañeros de raza trabajarían con ardor para conseguir la justicia a la que tienen perfecto derecho". Se justificaba esta interpretación afirmando que "el Día del Indio no puede ni debe ser fiesta para el blanco sino de gestión bienhechora en pro del indio de nuestros países". Con motivo de la celebración, el IIE también envió una circular a todos los municipios, pidiendo que no se alterasen los nombres de los sitios históricos, defendiendo así la tradición indígena ${ }^{16}$.

Por último, entre las noticias de celebraciones del 19 de abril, encontramos también la República Dominicana y Cuba, cuyos actos, celebrados en 1945 y 1949 respectivamente, tuvieron un cariz literario, algo lejano del criterio original, si bien en el caso dominicano también hubo referencia a la labor desarrollada por el III ${ }^{17}$.

Más allá del continente, en España también se celebró esta festividad en la fecha establecida en Pátzcuaro según las noticias del Boletín. Por iniciativa del Seminario de Estudios Indigenistas de la Universidad de Madrid, dirigido por Manuel Ballesteros, se realizaron distintas actividades desde 1954 dentro de una interpretación muy favorable del indigenismo interamericano que Ballesteros defendió en su libro Indigenismo Americano, de 1961, y en su propia trayectoria académica, participando además en los congresos indigenistas interamericanos.

Para terminar este epígrafe, cabe mencionar los cinco países que celebraron el Día del Indio pero en fecha distinta al 19 de abril: Bolivia, Costa Rica, Estados Unidos, Perú y Uruguay. En el caso de Costa Rica y Uruguay no sabemos exactamente cuándo se estableció, pero en 1946 Costa Rica tuvo una "Semana del Indio" entre el 8 y el 13 de octubre, organizada por el instituto indigenista nacional, activo desde 1944, y en

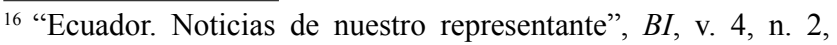
p. 116-122, jun. 1944. La noticia (120-122) es parte del informe acerca de las actividades indigenistas presentado por Víctor Gabriel Garcés, entonces representante del III en Ecuador y secretario del IIE.

${ }^{17}$ Fueron organizados por el centro ateneísta "Amor al Estudio" en la Republica Dominicana y por la Sociedad Colombista Panamericana en Cuba: "República Dominicana. El Día del Indio", $B I$, v. 5, n. 2 , p. 190, jun. 1945; "Cuba. Homenaje al Indio", BI, v. 9, n. 2, p. 142-145, jun. 1949 .
}

Uruguay el Instituto Uruguayo de Estudios Indigenistas (filial del III) organizó un acto en la Universidad de Montevideo, el 22 de mayo del mismo año ${ }^{18}$. Por lo tanto, las propias instituciones indigenistas nacionales no necesariamente reivindicaron el 19 de abril como Día del Indio.

Además, los casos de Estados Unidos y, sobre todo, de Bolivia y Perú, nos indican que el Congreso de Pátzcuaro de 1940 puede ser un falso punto de partida para el análisis de la efeméride, ya que en estos países el Día del Indio fue establecido con anterioridad, desde 1916, 1930 y 1937, respectivamente. Aunque con una longeva y difundida celebración, en Estados Unidos el día del indio se mantuvo en el ámbito nacional, incluso estatal, sin ninguna referencia al indigenismo interamericano ${ }^{19}$.

En Bolivia, la festividad se instituye en 1937, cuando el presidente Germán Busch decreta el Día del Indio en la fecha del " 2 de agosto en homenaje a la fundación del primer núcleo de Educación Indígena y Campesina en la República (Warisata)" (PÉREZ, 1962, p. 251). La referencia es al experimento de Elizardo Pérez con la Escuela Profesional de Indígenas de Warisata, que en la fecha estaba en su momento de auge, mientras Pérez era director general de educación "indigenal y campesina". En el Boletín encontramos solo tres referencias a la celebración en Bolivia: dos en 1942 y una en 1953. En 1942, la primera noticia se refiere a la celebración del 19 de abril y transcribe una nota de El Diario de La Paz acerca de instrucciones para las escuelas dictadas por Vicente Donoso Torres. Es decir, parecía asumirse la orientación pedagógica de la resolución de Pátzcuaro. La segunda, a la celebración del 3 (sic) agosto en Warisata, con una breve nota acerca de un desfile de niños, danzas autóctonas, alocuciones por varias autoridades y exposiciones ${ }^{20}$. Y en 1953 , en un apartado titulado " 2 de agosto 1952 " incluido en el informe del Instituto Indigenista Boliviano. Según esta nota, el Instituto Indigenista Boliviano (IIB) "realizó un imponente desfile cívico de cerca de 10,000 campesinos, del Alto de La Paz hasta la Plaza

\footnotetext{
18 "Costa Rica. Semana del Indio", BI, v. 6, n. 1, p. 28, mar. 1946 "Uruguay. El día del indio", BI, v. 10, n. 4, p. 354-355, dic. 1950. 19 "La celebración del Día del Indio Americano - 24 de septiembreen el Estado de New York", BI, v. 16, n. 1, p. 42-45, mar. 1956. Indian Affairs (IA) United States Department of the Interior, "A History of National Native American Heritage Month: The Nation's Efforts to Honor American Indians and Alaska Natives" (http://www.bia.gov/DocumentLibrary/HeritageMonth/. Acceso: 18 mayo 2016.

20 "Bolivia. Día del Indio", BI, v. 2, n. 3, p. 9, sept. 1942. "Bolivia. Día del Indio", $B I$, v. 2, n. 4, p. 11, dic. 1942.
} 
Murillo"21. Poco antes de esta celebración, en abril, se había creado el Ministerio de Asuntos Campesinos y el IIB pasó a depender del Ministerio de Asuntos Campesinos, bajo la Dirección General de Tierra y Colonización ${ }^{22}$. Al año siguiente, el Movimiento Nacional Revolucionario firmará la reforma agraria en la localidad cochabambina de Ucureña el 2 de agosto, una elección que establecía una relación simbólica con Warisata.

En Perú, el Día del Indio fue establecido en 1930 por decreto del presidente Leguía para que se celebrara el 24 de junio de cada año, justificando la elección por ser el día de las fiestas de San Juan en las pampas del Amacaes y por la "costumbre inmemorial" de las comunidades indígenas de festejar la misma fecha. Se indica además que en las escuelas se dicten conferencias especiales para enaltecer la "pasada grandeza" y las proyecciones de la cultura indígena en el continente (DIRECCIÓN GENERAL DE ASUNTOS INDÍGENAS, 1948, p. 226-227). La fiesta de Amancaes tenía su origen en una peregrinación religiosa católica que se remonta a 1582 . Y la costumbre inmemorial de las comunidades indígenas era nada menos que el Inti Raymi incaico ${ }^{23}$. Confluyen así en un mismo día distintos tipos de celebraciones con sus propios recorridos, junto a una nueva disposición de carácter cívico-patriótica. A pesar de que en el Boletín no hay ninguna mención a la celebración del Día del Indio en Perú, con la excepción del escrito de Velasco Núñez, cabe destacar el simbolismo de la fecha del 24 de junio que se usará en 1949 para inaugurar el II Congreso Indigenista Interamericano y, al igual que en el caso boliviano, para promulgar la ley de reforma agraria en $1969^{24}$.

Después del panorama que acabamos de dibujar ${ }^{25}$, y recordando la afirmación de León-Portilla en 1961

\footnotetext{
21 "Bolivia. Informe del Instituto Indigenista Boliviano", $B I$, v. 13, n. 2, jun. 1953, p. 106-113. El apartado "2 de agosto 1952": p. $110-113$.

${ }^{22} B I$, v. 12, n. 2, p. 112-115, jun. 1952.

${ }^{23}$ M. Velasco Núñez, "El Día del Indio en el Perú: 24 de junio", $B I$, v. 16, n. $2 / 3$, p. $214-223$, agosto 1956 .

${ }^{24}$ En 1957, un decreto del presidente Manuel Prado ya había cambiado la denominación del Día del Indio por la de Día del Campesino (MARTÍN SÁNCHEZ, 2011, p. 217-225).

${ }^{25}$ Soy consciente de que, en este recorrido, y a pesar de su relevancia, no he analizado la relación entre las instituciones indigenistas, las celebraciones del Día del Indio y la situación política de los diferentes países. Más allá de la limitación del espacio, que hace imposible realizar aquí este análisis de forma adecuada, el objetivo principal de este apartado era valorar el alcance y la difusión continental de una celebración cuyo significado y eventual éxito residía en convertirse en una práctica identificadora de los indigenistas.
}

acerca de la difusión continental del Día del Indio, podemos concluir que la celebración se extendió rápidamente por el continente en los primeros años después de Pátzcuaro, lo que indicaría un cierto éxito del indigenismo interamericano en la difusión de la fecha y de las prácticas identificadoras, pero sin que esta extensión continental alcanzara suficiente continuidad. Irónicamente, coincidiendo con la difusión de la expresión de "Día panamericano del Indio" en lugar de "Día del Indio" en los años 1950, la celebración pierde repercusión continental y, en los años 1960, como veremos a continuación, hasta los propios directores del III pierden interés en la fecha.

\section{Los directores del III: entre Día del Indio y defensa del relato indigenista}

En el periodo entre 1942 y 1974, los directores del III pronunciaron discursos oficiales en ocasión del 19 de abril, en la mayor parte de los casos alocuciones radiofónicas, posteriormente publicados como editoriales en las revistas del Instituto ${ }^{26}$.

Después del primer discurso, escrito en 1942 por el guatemalteco Carlos Girón Cerna (entonces director de publicaciones y secretario del III), y a lo largo de casi veinte años, su autor fue Manuel Gamio (director del Instituto entre 1942 y 1960), mientras que en los años siguiente los directores Miguel León-Portilla, Gonzalo Aguirre Beltrán y Gonzalo Rubio Orbe dedicaron bastante menos espacio y atención a esta celebración, que, además de no recordarse todos los años como en el periodo anterior a 1960, desaparece de las revistas después de 1974.

Estas alocuciones y editoriales representan un conjunto de fuentes coherente y sistemático que, sin embargo, no ofrece una imagen de la evolución del pensamiento indigenista "del Instituto" a lo largo de estas tres décadas, sino que más bien nos remite al pensamiento indigenista "de Gamio". En lugar de presentar una evolución, su discurso se mantiene constante y casi inmutable a lo largo de esos casi veinte años, fijando algunos elementos fundamentales no tanto para la definición del Día del Indio, como para el propio discurso indigenista del cual se harán eco, por lo menos en

\footnotetext{
${ }^{26}$ Los discursos se publicaron en el Boletín Indigenista, América Indigena y Anuario Indigenista (éste último sustituye al Boletín Indigenista desde 1962).
} 
parte, otros actores, si bien ni todos ni de la misma manera $^{27}$.

Los editoriales incluyen varios temas, cuya relevancia queda explícita si los consideramos según dos vertientes principales. Por un lado, encontramos las cuestiones relativas a la propia celebración: tipo de fiesta, su origen y significado, el lugar adecuado para su realización, el papel de los indigenistas y de los indígenas. Por el otro, encontramos un discurso indigenista que, aprovechando la fecha para su difusión, se va conformando y reforzando año tras año, incluyendo dos elementos fundamentales: un relato acerca del pasado y del presente de los indígenas y de los países americanos, y una definición de la americanidad, de la nacionalidad y de la indianidad.

Cabe destacar que no hay discusión explicita sobre la denominación de esta celebración. El Congreso de Pátzcuaro usa la expresión "Día del Indio" y ésta es la denominación que se mantiene hasta que en 1951 se empieza a usar, por el representante del Instituto Nacional Indigenista (INI) mexicano, la expresión "Día Panamericano del Indio". Ésta se mantiene en los años posteriores y en 1954 se usa también con relación a Brasil. Finalmente, durante su mandato como director del III, Miguel León-Portilla usa en 1965 la expresión "Día Interamericano del Indio" y tanto Gonzalo Aguirre Beltrán como Gonzalo Rubio Orbe usarán la de "Día Americano del Indio", alternándola con la de "Día Panamericano". No es casual que estos cambios en la denominación coincidan con una progresiva "mexicanización" de la celebración (y del propio indigenismo interamericano), con la imposición

\footnotetext{
${ }^{27}$ Disiento, por lo tanto, de lo que afirma Miguel Rodríguez (2004) en su capítulo dedicado al Día del Indio (p. 125-159), que considera como una celebración que contrasta y contradice la celebración que es objeto principal de su estudio (el "Día de la Raza"). Según este autor, estos discursos representan un material coherente para seguir "la evolución de las concepciones sobre la indianidad, sobre lo que es indio y lo que no lo es, durante más de tres décadas" (RODRÍGUEZ, 2004, 16) y "un conjunto coherente y sistemático que da una imagen de la evolución del indigenismo a través de tres décadas de día del indio" (p. 129). En su análisis, no se alcanza a percibir tal supuesta evolución, ya que no sigue un orden cronológico y no identifica claramente el papel de los distintos oradores dentro del indigenismo interamericano. La participación de John Collier, por ejemplo, depende de su papel como presidente del Consejo Directivo del III (lo que obviamente no excluye que en el indigenismo interamericano haya influencia estadounidense y del propio Collier en el periodo inicial), así como la publicación de los discursos en español y en inglés no es indicio de "la influencia de los norteamericanos en la celebración" (p. 137), sólo depende del hecho de que el Boletín Indigenista es un boletín bilingüe. Por otra parte, estas aclaraciones no quitan valor al interesante estudio de la celebración del Día de la Raza por parte de Rodríguez, cuyo objetivo principal no es el análisis del Día del Indio, ni del indigenismo en su conjunto.
}

de una tendencia "panamericanista" en la que no todos los países juegan un papel equivalente y con la defensa de una supuesta extensión continental del Día del Indio que sin embargo no parece tener justificación real.

La celebración del Día del Indio es definida desde el primer momento como "fiesta de diversión para los indios". En el primer editorial, el único escrito por Carlos Girón Cerna ${ }^{28}$, hay una referencia directa a la resolución de Pátzcuaro y al doble objetivo de la celebración: estudiar el problema del indio actual y divulgar "los valores positivos, artísticos y culturales de la raza" y, al mismo tiempo, ofrecer diversión y festejos. Insiste en que los indígenas no deben ser "actores gratuitos" para la diversión de "blancos y mestizos" 29 , al ser una fiesta para ellos. Sin embargo, en éste como en los demás editoriales, el programa festivo está hecho "para" los indígenas, no "por" los indígenas, como queda todavía más claro, en 1943 y 1944, al usar Gamio la expresión de "suministrar" diversiones a los indígenas, añadiendo que deben ser adaptadas a "sus tradición y psicología" 30 o que deben incluirse "platicas y conferencias sencillas" ${ }^{\prime 31}$. Esta idea de la necesaria adaptación remite a una concepción de "inferioridad cultural/intelectual", y no solo material, que aparece en otras ocasiones y que matiza la reiterada declaración de Gamio de que las teorías sobre la inferioridad de los indígenas son erróneas. Al mismo tiempo, también Gamio, como ya Girón Cerna, insiste en el papel del indígena como "actor y espectador" de la celebración ${ }^{32}$. Quedan así establecidos los respectivos papeles de indigenistas e indígenas: los primeros, encargados de diseñar y "adaptar" el programa ${ }^{33}$, los segundos, dedicados a disfrutar de su día, como un paréntesis necesario en una vida de miseria y dolor. Por ello, el lugar de la celebración no puede ser solo la ciudad -donde la celebración es útil para llamar la atención sobre el indígena y sus problemas, cumpliendo con el objetivo de estudio y divulgación- sino el campo, donde no

\footnotetext{
${ }^{28} \mathrm{Su}$ renuncia, con fecha de 30 de marzo, se publicará en el siguiente número del $B I$. Girón Cerna, quien tuvo un papel importante en los inicios del III, desaparece, de hecho, del Instituto en coincidencia con el nombramiento a director de Manuel Gamio. 29 "El día del Indio", BI, v. 2, n. 1, p. 2, mar. 1942.

30 "El día del Indio", $A I, 3$, n. 1, p. 5, enero 1943.

31 "Difusión continental en el Día del Indio", $B I$, v. 4, n. 1, p. 2, mar. 1944.

32 "El día del Indio", $A I$, v. 3, n. 1, p. 7, enero 1943

33 "Conceptos expresados por el nuevo director", $A I$, v. 2 , n. 2 , p. 7-9, abr. 1942. Más en general, en su primer editorial, Gamio indica que el papel de los indigenistas es poner "sus recursos y capacidad científica al servicio de los intereses y derechos de los indios" (p. 9).
} 
hay fácil acceso a diversiones y los único refugios a una vida de mucho trabajo y escasa alimentación son el culto dogmático y el alcohol ${ }^{34}$. Sin embargo, la realización de la celebración en el campo se dificulta por la necesidad de desplazarse y por los obstáculos para comunicarse con "los que solo hablan lenguas aborígenes", por lo que se propone la adopción de una solución práctica y económica, que de hecho es la que ya se está utilizando: el sistema de radio-emisión ${ }^{35}$.

La propia explicación de la necesidad de que el Día del Indio sea una fiesta de diversión está relacionada con la otra vertiente de estos editoriales: la configuración del discurso indigenista, especialmente con la elaboración de un relato acerca del pasado y del presente de los indígenas y de los países americanos. Este relato es coherente a lo largo de todo el periodo y, en 1961, el siguiente director del III, Léon-Portilla, lo resume en una sola frase: "el pasado grandioso y el presente abundante en problemas". El momento histórico crucial es la Conquista y si es cierto que Gamio recuerda, en dos ocasiones, "lo avanzado de la cultura precolombina" 36 y a "esos hombres que ayer edificaron civilizaciones de maravilla" ${ }^{37}$ en un tiempo en que incluso existía una "intensa movilidad geográfica", insiste bastante más en la descripción del presente y del pasado pos-Conquista. El "pasado grandioso" queda muy lejano en el discurso de Gamio, tan lejano que de hecho, según él, los indígenas actuales han perdido conciencia y memoria de ello. Solo quedan unas cuantas "supervivencias culturales de origen precolombino" 38 , perjudiciales en su mayoría $\mathrm{y}$, obviamente, anacrónicas, siendo positivas solo las de carácter artístico y ético, que deberían conservarse y hasta estimularse. Estas supervivencias, el "arraigo de estas tradiciones y costumbres" ${ }^{\prime 3}$, son la causa de la lentitud del progreso de los países con población indígena.

La descripción de la situación actual, empeorada por los peligros de la segunda guerra mundial y del racismo nazi, tiene estrecha relación con un relato histórico sin solución de continuidad sobre la situación de los indígenas desde la Conquista, algo que habría

\footnotetext{
34 "El día del Indio", $A I$, v. 3, n. 1, p. 5, enero 1943.

35 "Difusión continental en el Día del Indio", $B I$, v. 4, n. 1, p. 2 , 1944.

36 "Prejuicios raciales y complejos de inferioridad", $B I$, v. 5 , n. 2 , p. 100, jun. 1945 .

37 "De Pátzcuaro a Cuzco", $A I$, v. 8, n. 2, p. 87, abr. 1948.

38 "El rápido incremento demográfico y las supervivencias culturales de origen precolombino", $B I$, v. 18, n. 2, p. 90, jun. 1958.

39 “Conmemoración del Día del Indio", $B I$, v. 20, n. 2, p. 82, jun. 1960.
}

tenido profundas consecuencias hasta en el carácter, determinado por un "complejo de inferioridad, de timidez y fatalismo, que hicieron germinar las espadas de la Conquista, las encomiendas de la Colonia y el prolongado olvido de los mismos gobiernos republicanos" ${ }^{40}$. Esta situación histórica se considera como la causa fundamental del "ancestral y explicable pesimismo del alma autóctona", ya que la inicial "altiva y ambiciosa personalidad" del indígena ha sido quebrada por la Conquista, la Colonia y la República ${ }^{41}$. Los elementos del carácter del indígena se enfatizan aún más en la mujer indígena, en consecuencia de una vida aún más dura: "la mujer es del todo retraída, silenciosa, hermética"42.

Todo el pasado queda resumido en "cuatro largas centurias de tragedia y dolor" ${ }^{\prime 3}$. Esta idea se repite a lo largo de todo el periodo y en 1956 se define a los indigenas explícitamente como "victimas" de la conquista y de la colonia ${ }^{44}$. Este discurso de Gamio, que encuentra la explicación en una causa histórica, pero tan interiorizada que termina siendo parte de la "naturaleza indígena", es asumido por León-Portilla en su primer editorial de 1961. No sorprende que, a consecuencia de este relato acerca del pasado, las condiciones actuales de los indígenas sean "descritas" en términos muy negativos:

la salud de los habitantes así como sus problemas psicológicos son atendidos por empíricos curanderos y brujos, las técnicas agrícolas e industriales son primitivas, las herramientas deficientes, la alimentación exclusivamente vegetariana, la indumentaria elemental principalmente entre los varones que en considerable número andan descalzos o con huaraches o sandalias, la habitación insalubre carente de mueble y en la que es general la promiscuidad, las supersticiones e ideas y conceptos convencionales sobre ellos mismos y el mundo que los rodea $^{45}$.

Con la única excepción de la "pequeñas industrias artísticas" que sí pueden tener interés y un "buen

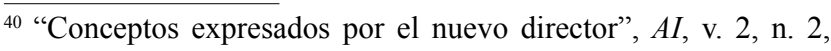
p. 7, abr. 1942.

41 "Prejuicios raciales y complejos de inferioridad", $B I$, v. 5, n. 2, p. 98 , jun. 1945.

42 "La mujer indígena", $B I$, v. 15, n. 2, p. 106, jun. 1955.

43 "La identificación del indio", $A I$, v. 6, n. 2, abr. 1946, 99.

44 "La inmigración en América", BI, v. 16, n. 2/3, agosto 1956 , 106.

45 "El rápido incremento demográfico y las supervivencias culturales de origen precolombino", $B I$, v. 18, n. 2, jun. 1958, 90.
} 
mercado sobre todo entre los turistas extranjeros" ${ }^{\text {" }}$, la situación es reiteradamente considerada desastrosa, una continuación del pasado: "su vida de ayer y hoy ha sido y es de servidumbre, miseria, dolor e inferioridad" ${ }^{47}$. Los indígenas son "los hijos más desvalidos de América", el indígena es "ese paria todavía irredento" "48: más que vivir "vegetan". Dentro del conjunto indígena, los monolingües forman "el sector demográfico más desvalido, aislado y escarnecido de América"49.

El presente y el futuro de los países están supeditados a la superación de esta situación, que representa un obstáculo al progreso y bienestar, no solo por las condiciones de vida, sino porqué "la nacionalidad no puede tener una existencia efectiva si la población es heterogénea" ${ }^{50}$. Sobre todo en sus últimos editoriales, a finales de los '50, Gamio reitera así una idea ya presente en su Forjando Patria (1916), en la que no hay posible nación sin homogeneidad.

Este relato acerca del pasado y del presente es bastante útil para reivindicar la legitimidad de la acción indigenista, sobre todo de aquella supuestamente fundada en la "ciencia". En varias ocasiones se recuerda que, incluso en la época colonial, hubo intentos de mejorar las condiciones de vida de estos grupos, pero de forma poco eficaz, y que solo en el siglo XX, con el indigenismo continental (el que el propio III representa), se ha empezado a enfrentar el problema con "cierta inspiración científica" " : primero, adoptar una "metodología científica integral" para conocer al indígena y, segundo, derivar los medios prácticos y formular medidas ${ }^{52}$. De paso, en la defensa de la "cientificidad" del indigenismo, Gamio procura alejarse de las "elucubraciones puramente sentimentales y propuestas utópicas" que también estuvieron presentes en Pátzcuaro ${ }^{53}$. Lo que hay que

\footnotetext{
46 "Conmemoración del Día del Indio", $B I$, v. 20, n. 2, jun. 1960,82 .

47 "Congresos indigenistas, investigación, financiación", $B I$, v. 9, n. 2 , jun. $1949,114$.

48 "De Pátzcuaro a Cuzco", $A I$, v. 8, n. 2, abr. 1948, 87; "Editorial. Congresos indigenistas, investigación, financiación”, $B I$, v. 9, n. 2, jun. 1949, 114; "Editorial. La acción indigenista oficial y particular", $B I$, v. 13, n. 2, jun. 1953, 90.

49 "Los grupos indígenas primitivos", $B I$, v. 14, n. 2, jun. 1954, 86. Algo ya presente en el editorial de 1953 y que se reitera en 1958.

50 "Conmemoración del Día del Indio", BI, v. 19, n. 2, p. 62, jun. 1959. La relación entre escaso o lento progreso y presencia de población indígena está explicita también en los editorial de 1956, 1958 y 1960.

51 "Comentarios sobre el desarrollo del programa del Punto Cuarto con referencia a la población aborigen de América", $B I$, v. 10, n. 2 , p. 116, jun. 1950 .

52 "Congresos indigenistas, investigación, financiación", $B I$, v. 9, n. 2, p. 116, jun. 1949.

53 "De Pátzcuaro a Cuzco", $A I$, v. 8, n. 2, p. 83, abr. 1948.
}

hacer es "enseñar al indio a vivir mejor" ${ }^{54}$. Y, si bien en este caso menciona la aportación fundamental de los maestros rurales, todo su discurso entre 1942 y 1960 está orientado a destacar el imprescindible papel de los indigenistas en poner "sus recursos y capacidad científica al servicio de los intereses y derechos de los indios", mediante un recorrido que va desde el estudio a la propuesta de solución y su aplicación concreta ${ }^{55}$. Podríamos afirmar que no sólo configura un discurso coherente a lo largo de estas dos décadas, sino que sus características fundamentales ya estaban presentes en sus primeros escritos de los años 1910.

Por otra parte, cabe destacar que, junto a las valoraciones acerca de las condiciones de vida de los indígenas, se configura otra definición de la indianidad, esta vez con matiz positivo, en relación con la idea de nacionalidad y de americanidad y con la propia celebración del Día del Indio. Se insiste en una unidad continental del indígena con una frase repetida y que adoptará también el siguiente director del III, Miguel León-Portilla, así como muchos otros indigenistas: "desde el esquimal de Alaska hasta el indígena de la Tierra del fuego, todos ellos forman un gran familia" 56 . Se admite la existencia de diferencias, pero recalcando "cierta analogía fundamental" que, sin embargo, no se explica, más allá de una referencia cultural genérica: "probablemente les corresponde la misma procedencia geográfica, son análogas sus características culturales y abrigan un no expresado pero latente espíritu de solidaridad" ${ }^{57}$. Una vez más, es tarea de los indigenistas despertar y promover esta solidaridad, ya que los propios indigenas, al vivir aislados y sin medios económicos, no pueden lograr un contacto directo, con alguna excepción como el propio congreso indigenista de Pátzcuaro. De allí surge el proyecto del III de recopilación de canciones, danzas y motivos musicales, y la organización de una "Exposición Interamericana de artes e industrias indígenas" 58 , para que el acercamiento entre los grupos indígenas sea mediante las expresiones artísticas que, recordemos, son las únicas "supervivencias cultu-

\footnotetext{
54 “Conmemoración del Día del Indio”, $B I$, v. 20, n. 2, p. 84, jun. 1960.

55 "Conceptos expresados por el nuevo director", $A I$, v. 2, n. 2, p. 9 , abr. 1942.

56 "Conceptos expresados por el nuevo director", $A I$, v. 2, n. 2, p. 8, abr. 1942 .

57 "Exposición interamericana de artes e industrias indígenas, y la conferencia de seguridad social", $A I$, v. 12 , n. 4, p. 267 , oct. 1952.

${ }_{58}$ Ambos proyectos se refieren en el editorial de 1951, BI, v. 11, n. 2, p. 110-112, jun. 1951. De ambos hay abundante material en el AHIII.
} 
rales de origen precolombino" que Gamio considera positivas. También rescata al indígena como raíz de la americanidad y de un casi natural panamericanismo: "La más pura fuente de la americanidad, el más vigoroso nexo que liga a los hombres de este Continente con el suelo en que viven es el indígena que alienta desde Alaska hasta Patagonia" y "Los treinta millones de indios $[\ldots]$ son no sólo la raigambre y la esencia del más tradicional y legitimo panamericanismo, sino que también constituyen la palanca fundamental del trabajo y de la producción". No deja de recordar, sin embargo, sus "condiciones de miseria e inferioridad material e intelectual" 59 . Esta relación entre el indígena y la identidad continental no exime del considerar su situación actual como un obstáculo al progreso y al correcto desarrollo de las distintas naciones.

En los años 1960 (cuando los editoriales sobre la celebración pierden su recurrencia anual) Miguel LeónPortilla heredará este discurso de Gamio, enfatizando todavía más la distancia entre el pasado glorioso de las antiguas culturas -de las que queda testimonio arqueológico y literario- y el presente necesitado de desarrollo integral. Sin embargo, León-Portilla reformula este aspecto del discurso para reivindicar un espacio en el mundo indigenista para los, que como él mismo, estudian "las antiguas culturas americanas", junto a los indigenistas que se ocupan de la realidad presente. De esta manera, introduce un elemento que no estaba presente antes o que por lo menos no se enfatizaba: el reconocimiento de que "las creaciones de los pueblos indígenas son herencia cultural nuestra y también del hombre en general". El indigenismo reivindica esta herencia y por lo tanto "son indigenistas quienes consagran su vida al estudio del arte prehispánico, de la literatura y en una palabra de las antiguas culturas americanas" ${ }^{\prime 60}$. Pero, también lo son los antropólogos que buscan una "comprensión integral de la realidad de las comunidades indígenas" y que planifican "procesos de cambios" en los rasgos que dificultan su "desarrollo y participación activa" (las que Gamio llamaba "supervivencias perjudiciales"). El "destino" del indigenismo es "propiciar la nueva fisionomía mestiza de nuestros pueblos" ${ }^{\prime}$. Este sentido del indigenismo es el que encontramos solo en el siglo XX en los proyectos "con un criterio integral, genuinamente antropológico" $"$.

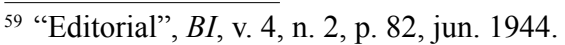

60 "El indigenismo interamericano y la antropología social", $A I$, v. 26, n. 3, p. 207, jul. 1966 .

${ }^{61}$ Ibídem, p. 208 y 211.

62 "Discurso del Dr. Miguel León-Portilla el Día Interamericano del Indio", $A I$, v. 25 , n. 3, p. 267 , jul. 1965.
}

En otras palabras, el capital social propio del indigenismo es el desarrollo de la antropología aplicada, consecuencia de la toma de conciencia de la realidad, y en esto reside su "cientificidad".

En 1961, el indigenismo latinoamericano era resumido por el nuevo director del III en dos figuras: Manuel Gamio y el brasileño Cándido Mariano da Silva Rondón ${ }^{63}$, algo que reiterará en su segundo editorial como director ${ }^{64}$. Al recordar el Congreso de Pátzcuaro, origen del Día del Indio y, sobre todo, del proprio III, es borrado por completo el nombre de Moisés Sáenz, inspirador de ambos.

Al finalizar la década, los discursos de otro director, Gonzalo Aguirre Beltrán, revelan una situación bastante distinta en la que el indigenismo interamericano y, en el caso concreto, el mexicano, deben defender su legitimidad y representatividad. En 1967, Aguirre Beltrán pronuncia la oración del Día del Indio en Guelatao, Oaxaca, la patria natal de Benito Juárez, y enfrenta explícitamente las acusaciones al indigenismo de ser una "prolongación de la política colonial", "de representar una moción discriminatoria que pretende dar al indio un trato privilegiado" y "de quererlo conservar en su escenario natural para utilizarlo como laboratorio de investigación antropológica, como objeto de exhibición turística y museográfica". Para aclarar qué es el indigenismo, Aguirre Beltrán interpreta la trayectoria del "indio" Juárez como el alejamiento de la comunidad de origen para actuar "como no indio" y encabezar un movimiento de reforma que fue "indigenista". Defiende así su conocida definición del indigenismo: "El indigenismo no es una política formulada por indios para la solución de sus propios problemas sino la de los no-indios respecto a los grupos étnicos heterogéneos que reciben la general designación de indígenas" ${ }^{65}$. De esta manera, excluye a los indígenas de un papel activo en el campo indigenista, algo que se le reprochará de inmediato. Pero hay que señalar también que, por primera vez en un discurso del director del III en ocasión del Día del Indio, Aguirre Beltrán introduce el "elemento de justicia social" para diferenciar la política indigenista del siglo XX de sus antecedentes coloniales (la política de "segregación") y decimonónicos (la política de "incorporación") y aproxima esta política indigenista, que tiene en cuenta

\footnotetext{
63 "Editorial. Conmemoración del Día del Indio", $B I$, v. 21, n. 2, p. 82-89, jun. 1961.

64 "Discurso del Dr. Miguel León-Portilla el Día Interamericano del Indio", $A I$, v. 25, n. 3, p. 267-278, jul. 1965.

65 "Un postulado de política indigenista", $A I$, v. 27, n. 3, p. 559 y 562 , jul. 1967.
} 
los postulados del relativismo cultural (dando valor a las lenguas, creencias y costumbres indígenas) y los propósitos de integración, mejoramiento y justicia social, a la definición de desarrollo de comunidad formulada por las Naciones Unidas.

Las palabras de Aguirre Beltrán no dejaron indiferente a Onésimo Ríos Hernández quien, en representación de la Asociación de Profesionistas e Intelectuales Indígenas de México, rebatió sus afirmaciones. Desde 1950, Ríos había participado en la celebración mexicana del Día del Indio, como presidente de la Confederación de Jóvenes Indígenas (CNJI), transformada después en Confederación Nacional de Jóvenes y Comunidades Indígenas (CNJCI). En su escrito, señala que Juárez sólo fue un caso aislado, no representativo de una tendencia y sin relación con "la discusión del problema indígena actual". Reivindica que, desde 1949, la CNJI sostuvo "como bandera de lucha la necesidad de que el llamado 'problema indígena' se pusieran en mano de los propios indígenas ya capacitados para ello". Frente al indigenismo como política formulada por "los no-indios" de Aguirre Beltrán, Ríos defiende la participación legitima de los indígenas (si bien solo de los "aculturados" o "capacitados") en el indigenismo. Curiosamente, para apoyar el "punto de vista de [los] indios frente a los indigenistas", recuerda el editorial de Gamio de 1947 y su decepción sobre la forma en que se habían realizado los programas indigenistas en los años anteriores. Usa así el recurso de la "figura mítica" del indigenismo, a pesar de que, en la postura de Gamio, el único espacio para los indígenas en el indigenismo era su papel de destinatarios de políticas y proyectos ${ }^{66}$.

En 1971, es nuevamente Aguirre Beltrán quien pronuncia el discurso del Día del Indio. En América Indigena se publica junto al de Alberto Medina Pérez, "representante de la juventud indígena", bajo un mismo título, como si fueran coautores, cuando en realidad se trata de dos alocuciones pronunciadas por separado. En abril de ese año, acababa de ser nombrado nuevo director del III el ecuatoriano Gonzalo Rubio Orbe. Aguirre Beltrán, director saliente, reunía en ese momento los cargos mexicanos de director del INI y de subsecretario de cultura popular de la SEP. Al recordar el Congreso de Pátzcuaro, Aguirre Beltrán lamenta la existencia de corrientes contrarias de opinión, que habría deteriorado la unanimidad de 1940, incluso en relación a la celebración del 19 de abril: "Unos han

${ }^{66}$ Onésimo Ríos H., "Consideraciones en torno a 'Un postulado de política indigenista’”, $A I$, v. 28, n. 1, p. 292 y 294, enero 1968. olvidado la conmemoración o le restan importancia, otros expresan su repulsa al planteamiento de Pátzcuaro mudando la designación de día del indio por la de día del campesino" ${ }^{\circ}$. México, sin embargo, "permanece fiel al postulado original de Pátzcuaro; por eso, año con año $[. .$.$] continúa recordando al indio y llamándolo$ por su nombre" 68 . Por su parte, la alocución de Medina Pérez está muy lejos del tono crítico y reivindicativo que tenía Ríos unos años antes: al contrario, retomando el consolidado discurso indigenista sobre el pasado colonial y las independencias (y solo salvando el papel de "indios" como Juárez y Altamirano), se resalta el cambio inaugurado en México con la revolución y, más tarde, el congreso de Pátzcuaro como "grito de redención para los grupos nativos del continente", expresando gratitud por el fundador del INI, Alfonso Caso y por el presidente mexicano de entonces, Echevarría ${ }^{69}$.

En el último discurso del Día del Indio publicado en una revista del III, el nuevo director Gonzalo Rubio Orbe reitera una vez más la idea de una celebración dedicada a la "realidad" y no sólo "de contenido romántico y sentimental". Esa realidad es de marginación y formas de dependencia "incompatibles con los tiempos que vivimos, con los Derechos Humanos y Sociales que hemos proclamado y que nos hemos comprometido a conquistar y defender". Poco antes de que se adopte oficialmente el "indigenismo participativo", Rubio Orbe reconoce los esfuerzos "de los propios indígenas en la acción a favor de su causa y de sus pueblos" y que esa participación, junto a la eliminación de la discriminación, la explotación y el abuso, "será la mejor y más efectiva fuerza para su desarrollo y nuevo destino" 70 .

\section{En representación del III: relato indigenista interamericano y visiones nacionales}

Además de los directores, también hablaban, a nombre del III, los presidentes (o vicepresidentes) del

\footnotetext{
${ }^{67}$ La referencia es a Perú y al cambio de denominación de "indio" por "campesino" de la Ley de Reforma Agraria de Velasco Alvarado.

68 "Alocución del Dr. Gonzalo Aguirre Beltrán", bajo el título de "Celebración del Día Americano del Indio", $A I$, v. 25, n. 2, p. 482-488, abr. 1971. Citas en p. 483.

69 "Alocución del Prof. Alberto Medina Pérez", bajo el título de "Celebración del Día Americano del Indio", $A I$, v. 25, n. 2, p. 488-492, abr. 1971. Cita en p. 491.

70 “Celebración del Día Americano del Indio", AnI, v. 34, p. 69-72, 1974.
} 
Consejo Directivo del Instituto (en una sola ocasión la representación recayó en el presidente del Comité Ejecutivo). Aquí cabe destacar que, a pesar de tener oficialmente el mismo cargo, su papel e importancia en el proyecto del indigenismo interamericano podía ser muy distinto, pues no necesariamente quienes recubrían estos cargos -los diplomáticos de los distintos países con sede en México- tenían especial interés en el indigenismo, sino que cumplían con la representación de su país en el III.

No así el caso de John Collier, presidente del Consejo Directivo del III entre 1942 y 1946, quien fue una figura de la máxima relevancia desde los inicios de este proyecto, cuando organizó, junto a Moisés Sáenz, el Congreso de Pátzcuaro. Su protagonismo, en esos primeros años, coincidía con su importante papel en la renovación de la política indigenista de Estados Unidos durante la administración Roosevelt, el Indian New Deal, (PHILP, 1977; GUERRIER, 2007). Por ello, las primeras alocuciones pronunciadas por Collier en el Día del Indio defienden con claridad este proyecto continental desde una interpretación estadounidense del mismo, con sus peculiaridades de lenguaje y de contenido. Coinciden con los años de la segunda guerra mundial y su final, lo que tiene implicaciones importantes en la forma en que se está defendiendo el papel de Estados Unidos en el continente: la situación era favorable a los proyectos interamericanos, como el indigenismo, pero hacía muy difícil una cooperación hemisférica entre iguales, ya que dos países, México y Estados Unidos, mantuvieron un papel especial (GIRAUDO, 2012).

En 1944 y 1945, la guerra es la protagonista de los discursos de Collier. Define al Día del Indio como "el día hemisférico del Hombre Cobrizo [Red Indian]", tanto de los indígenas de la actualidad, como de sus antepasados, quienes "sufrieron una opresión como la que la victoria nazista y japonesa impondría a toda la raza humana". La colonización y el nazismo quedan así unidos ${ }^{71}$. Al año siguiente, reitera que el indígena "ha sido víctima del racismo por cuatros centurias, pero nunca ha albergado el racismo en su pecho", algo que debería recordarse en el Día del Indio, en un momento en que Alemania y Japón han intentado establecer el dogma racista y el sistema totalitario, sin lograrlo, gracias a la unión de "todas las sub-razas de todo el planeta" 72 . Sin embargo, hay otro elemento

\footnotetext{
71 "Alocución del Sr. John Collier", en "Celebración del día del indio", $B I$, v. 4, n. 2, p. 94, jun. 1944.

72 "Alocución del Sr. John Collier", en "Noticas del Instituto. El
} Día del Indio", BI, v. 5, n. 2, p. 106-111, jun. 1945. que se enfatiza como el resultado del cambio de la política indigenista en Estados Unidos: la caída de la cifra de mortalidad de los indígenas y el crecimiento exponencial de su productividad y consumo. El mismo cambio en los niveles de consumo y productividad en México o en los países andinos, donde la importancia cuantitativa de población indígena es mucho mayor, sugiere Collier, significaría "una vida mejor, más completa y segura para la población total de nuestro hemisferio" "73. Es, en otros términos, el mismo planteamiento de Gamio, cuando insiste en que los bajos niveles de vida de los indígenas son obstáculos al progreso de los países latinoamericanos y que su mejoría permitiría un mayor bienestar general, pero en este caso se presenta con la retórica de la defensa de la democracia y la libertad frente a los fascismos.

En su tercera y última alocución, Collier hace uso explícito de los elementos fundamentales que hemos identificados como parte del discurso indigenista que se elabora con la celebración: el relato acerca del pasado y del presente de los indígenas y de los países americanos, por un lado, y la definición de la americanidad y de la indianidad, por el otro. El lenguaje es, de nuevo, distinto al que tiene Gamio en los mismos años. Tras recordar la importancia de Pátzcuaro en identificar "el problema del indio americano" como algo concerniente a todo el hemisferio occidental, considera el Acta de 1940 como una anticipación (en la idea y en la práctica) de la Asamblea y de la Carta de las Naciones Unidas. Si esta última se ocupa de "las gentes desvalidas del mundo entero, las clases desposeídas y no privilegiadas y las masas y grupos étnicos", en Pátzcuaro se inició "uno de los mayores programas de autoayuda y autoredención de todo el Hemisferio". Los indígenas, además de representar la fuente de la americanidad, "el hecho que tienen de común nuestras Repúblicas Occidentales", son el lazo "de sangre" y "espiritual" con el continente asiático por tratarse de "una raza asiática". Con esta visión, se augura que el Día del Indio se celebre, en el futuro, en el mundo entero ${ }^{74}$. Adopta, así, una idea internacional, no sólo americana, de la indianidad.

Desde 1947, una nueva efeméride aparece en el calendario: el 14 de abril como "Día de las Américas". En las palabras del nuevo presidente del Consejo Directivo, el embajador de Perú Pablo Abril de Vivero,

\footnotetext{
73 "Alocución del Sr. John Collier", en "Celebración del día del indio", $B I$, v. 4, n. 2, p. 96, jun. 1944.

74 "Discurso del Sr. John Collier", en "Noticas del Instituto. Día del Indio", BI, v. 6, n. 2, p. 98-109, jun. 1946. Citas en p. 100, 102 y 108 .
} 
se deben "considerar aún como complementarias estas dos efemérides", al ser evidente que no es posible lograr la unidad continental si hay núcleos de población aborigen que permanecen "segregados de la familia de las naciones". Una visión maniquea y simplista del pasado americano asoma en sus palabras, especialmente cuando afirma que los elementos humanos que intervienen en el acaecer social se pueden reducir a solo dos categorías: esclavistas y libertadores ${ }^{75}$.

Los demás presidentes adoptan un relato sobre el pasado, y en consecuencia sobre el presente, que sigue las líneas que consolida Gamio en esos mismos años. Roberto Bilbao de la Vieja, vicepresidente del Consejo Director y embajador de Bolivia, recuerda los "cuatro siglos de una conducta agresiva y esclavista de los grupos colonizadores", atribuyendo esta actitud no sólo a los conquistadores, sino también a los criollos y a los mestizos después de las independencias ${ }^{76}$. Entre sus sucesores, el ecuatoriano Gustavo Pérez Chiriboga es el que, además de una clásica referencia a "las grandes masas indígenas, por cuatro siglos olvidadas, menospreciadas o explotadas" 77 , adopta con más claridad el relato completo, sobre todo en su discurso de 1955. Desde la Conquista, punto de inflexión crucial, al detener la evolución de las culturas existentes, pasando por la "servidumbre y esclavitud" y las lamentables condiciones de vida de los siglos coloniales en los que, afirma, "indios y españoles vivían en mundos distintos", hasta el siglo $\mathrm{XX}$, cuando las "inconexas actividades indigenistas" convergen en el indigenismo interamericano ${ }^{78}$. Tanto Pérez Chiroboga como sus antecesores, el peruano Oscar Vázquez Benavides y el nicaragüense Alberto Sevilla Sacasa, recuerdan la otra cara de este relato, la situación del presente: "el aislamiento, las dolencias, las angustias y la miseria material e intelectual de más de treinta millones de americanos", las "condiciones de vida subhumana", las "condiciones de inferioridad manifiesta" de los indígenas "del presente que no

\footnotetext{
75 "Discurso del Sr. Pablo Abril de Vivero", en "Noticas del Instituto. Día del Indio", BI, v. 7, n. 2, p. 106-109, jun. 1947. Citas en p. 106.

76 "Discurso de Don Roberto Bilbao la Vieja", en "El Instituto en el Día del Indio", $B I$, v. 8, n. 2, p. 90, jun. 1948.

77 "Mensaje del Dr. Gustavo Pérez Chiriboga, embajador del Ecuador en México y presidente del consejo directivo del Instituto Indigenista Interamericano", en "México. Día Panamericano del Indio", $B I$, v. 14, n. 2, p. 146, jun. 1954.

78 "Mensaje del Dr. Gustavo Pérez Chiriboga, embajador del Ecuador en México y presidente del consejo directivo del Instituto Indigenista Interamericano", en "México. Celebración del Día Panamericano del Indio", $B I$, v. 15, n. 2, p. 178-180, jun. 1955.
}

salen de su pasado"79. Al mismo tiempo, se exaltan la calidades de "una raza extraordinaria" 80 (por haber sobrevivido a este pasado), elemento que está directamente relacionado con la propia celebración. El peruano Oscar Vázquez Benavides recuerda, en 1949, el significado de un día en que "se exaltan las virtudes de la raza autóctona de América" y la plena identificación entre esta fiesta y el III, "ya que es el Indio, significación plena de sentido etnológico y social, el tema central de sus preocupaciones e iniciativas" $"$. Al año siguiente, el mismo Vázquez Benavides insiste sobre este segundo aspecto, el otro objetivo de la celebración: "recordar el deber que tenemos todos los americanos de trabajar en favor del mejoramiento de la raza aborigen del Continente" ${ }^{82}$, es decir, la tarea indigenista. Otros, como el nicaragüense Alberto Sevilla Sacasa, son menos optimistas sobre el Día del Indio, que todavía no es "una efeméride ya consagrada para una fastuosa celebración" $" 83$ : la que se exalta es la memoria de los antepasados (menciona a Cuauhtémoc, Atahualpa, Nicarao, Arariboia, Lempira), no sus descendientes. El ecuatoriano Jorge Villagómez Yépez también resalta el contraste entre "los hombres símbolos de los pueblos aborígenes" y "sus mismos pueblos [que] sucumben hasta el abatimiento y desolación" $"$.

Ambos relatos -sobre el pasado y sobre el presenteson funcionales a la reivindicación de una nueva etapa, la de "la revaloración del Indio como actitud colectiva" 85 , del "redescubrimiento del indio americano" $"$ : es decir, la etapa del indigenismo interamericano. Todos, de una manera u otra, consideran a Pátzcuaro o al III como el referente de esta tarea, resaltando el realismo, la actitud científica, la conciencia del "problema" y el haber "avanzado paulatinamente hacia la obra concreta, hacia

\footnotetext{
79 "Mensaje del Dr. Gustavo Pérez Chiriboga", 1954, p. 146; "Discurso del Dr. Oscar Vásquez Benavides", en "Noticias del Instituto. El Día del Indio", $B I$, v. 10, n. 2, jun. 1950, 124; "Discurso del Dr. Alberto Sevilla Sacasa", en "Noticias del Instituto. El Día del Indio", BI, v. 11, n. 2, p. 120, jun. 1951. 80 "Discurso de Don Roberto Bilbao la Vieja", 1948.

81 "Discurso del Dr. Oscar Vásquez Benavides", en "Noticias del Instituto. Celebración del Día del Indio", $B I$, v. 9, n. 2, p. 118, jun. 1949.

82 "Discurso del Dr. Oscar Vásquez Benavides", en "Noticias del Instituto. El Día del Indio", BI, v. 10, n. 2, p. 124, jun. 1950.

83 "Discurso del Dr. Alberto Sevilla Sacasa", en "Noticias del Instituto. El Día del Indio", BI, v. 11, n. 2, p. 120, jun. 1951.

84 "Mensaje del Dr. Jorge Villagómez Yépez, Embajador del Ecuador en México, quien habló a nombre del Instituto Indigenista Interamericano, cuyo consejo directivo preside", $B I$, v. 13 , n. 2 , p. 128, jun. 1953.

85 "Discurso de Don Roberto Bilbao la Vieja", en "El Instituto en el Día del Indio", $B I$, v. 8, n. 2, p. 90, jun. 1948.

86 "Mensaje del Dr. Jorge Villagómez Yépez", 1953, p. 132.
} 
la acción efectiva"87. Así, la celebración es la ocasión para recordar las actividades indigenistas, las del III y las de los distintos países, además de la necesidad de la cooperación interamericana, algo que se hace especialmente evidente desde 1950, con discursos como los de Vázquez Benavides ${ }^{88}$.

Alberto Sevilla Sacasa recuerda, en 1951, la necesidad de la "cooperación interamericana", alentada incluso por su país, a pesar de que "para Nicaragua el problema no se aplica sustancialmente" ${ }^{89}$. En 1953, Jorge Villagómez Yépez afirma que "la causa indigenista se abre paso ahora en pos de cumplidas realizaciones" $"$, para a continuación referirse a lo que se están realizando en México, Estados Unidos, Colombia, Brasil, Venezuela, Bolivia, Perú, Chile, Argentina, Uruguay, y Ecuador. Concluye con un símil entre el "descubrimiento" de Colón y el "redescubrimiento del indio americano" por parte del III. Gustavo Pérez Chiriboga, además de recordar la reciente celebración del III Congreso Indigenista (La Paz, 1954), exalta el avance que supone la acción concreta del indigenismo (frente a las anteriores actividades inconexas), lamentando sin embargo la falta de presupuesto para realizarla. En 1955, entre los institutos nacionales, además de México, destaca también a Guatemala, como ya hizo Vázquez Benavides ${ }^{91}$. Si en 1950, la referencia de Benavides a Guatemala resulta curiosa -justamente se trata de un país en el cual el indigenismo era ausente hasta los años 1940- pero explicable, ya que en 1945 se había fundado su instituto indigenista (IING) y el indigenismo vivía su "primavera", en 1955, después del golpe de estado, la situación era muy diferente, a pesar de que tras su suspensión, el IING reanudara parte de sus actividades y Guatemala sería la sede en 1959 del IV Congreso Indigenista (ADAMS, 2011).

El propio Pérez Chiriboga es quien, entre los representantes del III, defiende de forma más explícita, como ya mencionamos, un determinado relato acerca del pasado de los indígenas, y es también quien introduce en 1956 un elemento de cambio en este discurso ritual que por otra parte mantiene todos los otros elementos ya tradicionales. A consecuencia de la desposesión de sus "derechos humanos" que sufrió el "aborigen" 400 años antes, considera la celebración

\footnotetext{
87 "Mensaje del Dr. Gustavo Pérez Chiriboga", 1954, p. 148.

88 "Discurso del Dr. Oscar Vásquez Benavides", 1950, p. 124-130. Citas en p. 130.

89 "Discurso del Dr. Alberto Sevilla Sacasa", p. 120.

90 "Mensaje del Dr. Jorge Villagómez Yépez", 1953, p. 128.

91 "Mensaje del Dr. Gustavo Pérez Chiriboga", 1954, p. 148;

"Mensaje del Dr. Gustavo Pérez Chiriboga", 1955, p. 182.
}

como la ocasión de "recordarles [a los habitantes y gobiernos americanos que] existe un deber todavía no cumplido, una deuda aún no satisfecha y un equilibrio hasta hoy no establecido: la condición del indio" ${ }^{22}$. Es la primera vez que aparece la palabra "deuda" junta al "deber indigenista", algo muy distinto al lenguaje que usaba, en el mismo periodo, el director Manuel Gamio. En 1958, Carlos de la Espriella enfatizó la importancia del estudio de los grupos indígenas de Costa Rica como base para que "una legislación atinada les haya restituido derechos"93. Estas innovaciones contrastan con el discurso de los directores del III, pues no es hasta 1967 que Aguirre Beltrán introdujo la referencia a la "justicia social" y aún hasta 1974 que Gonzalo Rubio Orbe habla del Día del Indio como el día para "reclamar los derechos que tienen las comunidades aborígenes para una existencia digna y humana" $"$.

\section{Coda: un legado indigenista todavía inexplorado}

Cuando, en 1940, el Congreso de Pátzcuaro introdujo la celebración del Día del Indio, ésta se presentó como una nueva celebración, con ambición continental, destinada a "enaltecer al indio". Algunos países americanos, sin embargo, ya contaban con "un Día del Indio" en sus calendarios festivos, en fechas distintas a la establecida por el Primer Congreso Indigenista. Otros la introdujeron en cumplimiento del acuerdo allí firmado y en apoyo explícito al proyecto de un indigenismo interamericano. En ambos casos, funcionó más como práctica identificadora de los defensores del indigenismo (entre ellos, también indígenas) que como homenaje a los indígenas. El éxito inicial en su amplia difusión por el continente indicaría que se hubiera podido convertir en la celebración indigenista interamericana que preveían sus creadores, una fiesta que mientras homenajeaba al indígena -eso sí, al "indio mítico" y atemporal, a los héroes indígenas, más que a los indígenas contemporáneos-contribuyera a conquistar un espacio para un indigenismo que

\footnotetext{
92 "Discurso del embajador del Ecuador en México, Excmo. Señor Gustavo Pérez Chiriboga, presidente del consejo directivo del Instituto Indigenista Interamericano, con motivo de la celebración del Día del Indio", en "México. Celebración del Día Panamericano del Indio", $B I$, v. 16, n. 2/3, p. 172, agosto 1956.

93 "Discurso del embajador de Costa Rica en México, Exmo. Sr. Carlos de la Espriella, presidente del Consejo Directivo del III, con motivo del Día del Indio", $B I$, v. 18, n. 2, p. 130, jun. 1958.

94 “Celebración del Día Americano del Indio", AnI, v. 34, p. 69, 1974.
} 
se reivindicaba concreto, de acción y de alcance continental. El camino fue algo más tortuoso de lo previsto y, además de que Pátzcuaro se reveló en algunos casos un falso punto de partida, esa inicial difusión de la "nueva celebración" no parece haber tenido una clara continuidad en la mayor parte de los países, con las importantes excepciones de Argentina, Brasil y México. Al mismo tiempo, ofreció la ocasión para definir un relato sobre el pasado y el presente de los indígenas y de los países americanos que asignaba al indigenismo un papel crucial y legitimaba sus acciones.

Por otra parte, podemos considerar a esta celebración como un legado indigenista del que todavía tenemos que averiguar los efectos y las influencias en el largo periodo. El Día del Indio (el del 19 de abril) sigue, de hecho, paseándose en tierras americanas, conviviendo con otros días del indio, cambiando (en algunos casos) de nombre, confrontándose, solapándose y confundiéndose con otras celebraciones: ha renacido de las cenizas del indigenismo oficial para ser reivindicado en la actualidad por actores de los más dispares, incluidas organizaciones indígenas que han resignificado la efeméride. Aquí, hemos acotado nuestro análisis a las décadas centrales del siglo XX, a la edad de oro del indigenismo, por considerarlas las más relevantes para interpretar el significado del Día del Indio en el ámbito indigenista: queda abierto el camino para acercarse a las décadas posteriores y a los sorprendentes giros del presente, en el que, quizás, podemos encontrar más de una continuidad con el indigenismo de antaño, a pesar de su reiterado rechazo y de su declarada extinción.

\section{Referencias}

ADAMS, Abigail E. El indigenismo guatemalteco: atrapado entre la promesa del interamericanismo y la guerra frías. En: GIRAUDO, Laura; MARTÍN-SÁNCHEZ, Juan (Ed.). La ambivalente historia del indigenismo: campo interamericano y trayectorias nacionales, 1940-1970. Lima: Instituto de Estudios Peruanos, 2011. p. $99-132$.

BALLESTEROS GAIBROIS, Manuel; ULLOA SUÁREZ, Julia. Indigenismo Americano. Madrid: Ediciones Cultura Hispánica, 1961.

DAWSON, Alexander. Indian and Nation in Revolutionary Mexico. Tucson: The University of Arizona Press, 2004.

FREIRE, Carlos Augusto da Rocha. Indigenismo e antropologia. O Conselho Nacional de Proteção ao Índio na gesta Rondon (1938-1955). 1990. Dissertação (Mestrado) - Museu Nacional da Universidade Federal do Rio de Janeiro (UFRJ), Rio de Janeiro, 1990.
GIRAUDO, Laura. Un campo indigenista transnacional y "casi profesional": la apertura en Pátzcuaro (1940) de un espacio por y para los indigenistas. En: GIRAUDO, Laura; MARTÍNSÁNCHEZ, Juan (Ed.). La ambivalente historia del indigenismo: campo interamericano y trayectorias nacionales, 1940-1970. Lima: Instituto de Estudios Peruanos, 2011. p. 21-98.

GIRAUDO, Laura. Neither "Scientific" nor "Colonialist": The Ambiguous Course of Inter-American Indigenismo in the 1940s. Latin American Perspectives, v. 39, n. 5, p. 12-32, Sept. 2012. https://doi.org/10.1177/0094582X12447275

GUERRIER, Elizabeth. Applying Anthropology in the Interest of the State: John Collier, the Indian Office, and the Bureau of Sociological Research. History of Anthropology Annual, v. 3, n. 1, p. 199-221, 2007. https://doi.org/10.1353/haa.0.0024

LEWIS, Stephen E. ¿'Problema indígena’ o 'problema ladino’? Cincuenta años de pensamiento y políticas indigenistas en Chiapas. En: GIRAUDO; MARTÍN-SÁNCHEZ(Ed.). La ambivalente historia del indigenismo: campo interamericano y trayectorias nacionales, 1940-1970. Lima: Instituto de Estudios Peruanos, 2011. p. 251-291.

MARTÍN SÁNCHEZ, Juan. Indigenismo bifronte en el gobierno peruano de Velasco Alvarado: continuidad y alternativa, sierra y selva. En: GIRAUDO; MARTÍN-SÁNCHEZ (Ed.). La ambivalente historia del indigenismo: campo interamericano y trayectorias nacionales, 1940-1970. Lima: Instituto de Estudios Peruanos, 2011. p. $191-250$.

PHILP, Kenneth R. John Collier's Crusade for Indian Reform, 1920-1954. Tucson: University of Arizona Press, 1977.

RODRÍGUEZ, Miguel. Celebración de "la raza": una historia comparativa del 12 de octubre. México: Universidad Iberoamericana, 2004.

SOUZA LIMA, Antonio Carlos de. Tradições de conhecimento na gestão colonial da desigualdade: reflexões a partir da administração indigenista no Brasil. En: BASTOS, Cristiana; ALMEIDA, Miguel Vale de; FELDMAN-BIANCO, Bela (Org.). Trânsitos coloniais: diálogos críticos luso-brasileiros. Lisboa: Imprensa de Ciências Sociais, 2002. p. 151-172.

SOUZA LIMA, Antonio Carlos de. El indigenismo en Brasil: migración y reapropiaciones de un saber administrativo. En: PACHECO DE OLIVEIRA, João (Comp.). Hacia una antropología del indigenismo: estudios críticos sobre los procesos de dominación y las perspectivas políticas actuales de los indígenas en Brasil. Rio de Janeiro/Lima: Contra Capa/Centro Amazónico de Antropología y Aplicación Práctica, 2006. p. 97-125.

TORMO SANZ, Leandro. Don Manuel Ballesteros Gaibrois y el indigenismo. Anthropos, v. 162, p. 38-41, 1994.

TROYAN, Brett. Re-imaging the "Indian" and the State: Indigenismo in Colombia, 1926-1947. Canadian Journal of Latin American and Carribean Studies, v. 33, n. 65, p. 81-106, 2008. https://doi.org/10.1080/08263663.2008.10816941

VERGARA, Jorge Iván; GUNDERMANN Hans. Chile y el Instituto Indigenista Interamericano, 1940-1993. Una visión de conjunto. Chungara, Revista de Antropología Chilena, Arica, v. 48, n. 1, p. 127-144, 2016.

\section{Fuentes}

Archivo Histórico del Instituto Indigenista Interamericano (AHIII), Ciudad de México. 
Boletín Indigenista (BI), v. 1-21, agosto 1941-jun. 1961.

América Indígena (AI), v. 1-31, oct. 1941-jul. 1971.

Anuario Indigenista (AnI), v. 22-34, dic. 1962-dic.1974.

CONSELHO NACIONAL DE PROTEÇÃO AOS ÍNDIOS (CNPI). 19 de Abril. O dia do Índio. As comemorações realizadas em 1944 e 1945. Rio de Janeiro: Imprensa Nacional, 1946.

DIRECCIÓN GENERAL DE ASUNTOS INDÍGENAS. Legislación indigenista del Perú. Lima: Talleres Gráficos de la Penitenciaría Central, 1948.

INSTITUTO INDIGENISTA INTERAMERICANO. Acta Final del Primer Congreso Indigenista Interamericano. Patzcuaro,
Mich. México. En: Primer Congreso Indigenista Interamericano. México: Instituto Indigenista Interamericano, 1940. Vol. I, p. 1-42.

INSTITUTO INDIGENISTA NACIONAL. 19 de abril día del aborigen. Guatemala: José de Pineda Ibarra, 1970.

PÉREZ, Elizardo. Warisata. La escuela-ayllu. La Paz: Burillo, 1962.

RIBEIRO, Darcy. A politica indigenista brasileira. Rio de Janeiro: Ministério da Agricultura, 1962.

Recebido: 20 de mayo de 2016 Aprovado: 22 de julio de 2016

\section{Autora/Author:}

LAURA GIRAUDO laura.giraudo@csic.es

- Investigadora de la Escuela de Estudios Hispano-Americanos del Consejo Superior de Investigaciones Científicas (EEHA-CSIC), en Sevilla, España, desde 2008. Anteriormente (2006-2007) fue investigadora Ramón y Cajal en el Centro de Estudios Políticos y Constitucionales (CEPC) de Madrid e investigadora post-doctoral en la Universidad de Milán, Italia (2003-2005). Doctora en Historia por la Universidad

de Genova, Italia (2001).
Pesquisadora da Escuela de Estudios Hispano-Americanos do Consejo Superior de Investigaciones Científicas (EEHA-CSIC), em Sevilla, Espanha, desde 2008. Anteriormente (2006-2007) foi pesquisadora Ramón y Cajal no Centro de Estudios Politicos y Constitucionales (CEPC) de Madrid e pesquisadora pós-doutoral na Universidade de Milão, Itália (2003-2005). Doutora em História pela Universidade de Gênova, Itália (2001).

- Researcher at the Escuela de Estudios Hispano-Americanos of the Consejo Superior de Investigaciones Científicas (EEHA-CSIC), in Seville, Spain, since 2008. Previously (2006-2007) she was a "Ramón y Cajal" researcher at the Centro de Estudios Políticos y Constitucionales (CEPC) in Madrid and a post-doctoral fellow at the University of Milan, Italy (2003-2005). PhD in History by the University of Genova, Italy (2001). 